\title{
Understanding organisational culture for healthcare quality improvement
}

\author{
(c) (1) () $)$ OPEN ACCESS
}

Russell Mannion and Huw Davies explore how notions of culture relate to service performance, quality, safety, and improvement

\section{Russell Mannion professor ${ }^{1}$, Huw Davies professor ${ }^{2}$}

${ }^{1}$ Health Services Management Centre, University of Birmingham, Birmingham, UK; ${ }^{2}$ School of Management, University of St Andrews, St Andrews, UK

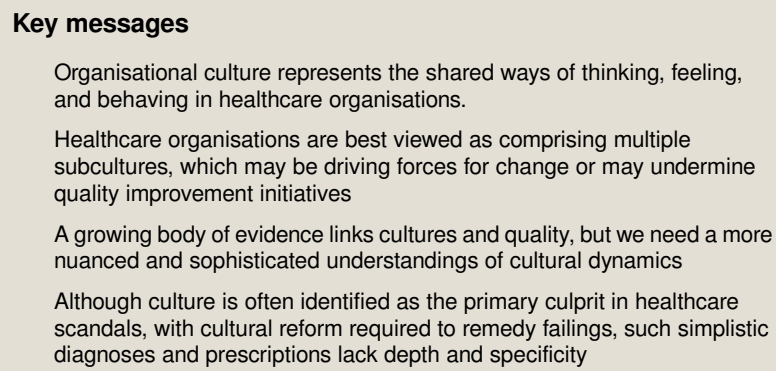

Healthcare organisations are best viewed as comprising multiple subcultures, which may be driving forces for change or may undermine quality improvement initiatives

A growing body of evidence links cultures and quality, but we need a more nuanced and sophisticated understandings of cultural dynamics

Although culture is often identified as the primary culprit in healthcare scandals, with cultural reform required to remedy failings, such simplistic diagnoses and prescriptions lack depth and specificity

If we believe the headlines, health services are suffering epidemics of cultural shortcomings. Extensive enquiries into failures and scandals in the NHS over several decades have indicated aspects of hospital culture as leading to those failings(box 1). ${ }^{12}$ The recent report into over 450 premature deaths at Gosport War Memorial Hospital mentions culture 21 times. ${ }^{3}$ After such reports, widespread and fundamental cultural change is typically prescribed as the remedy (box 1$).^{45}$
Box 1: Centrality of culture to healthcare scandals: from Kennedy to Francis

From lan Kennedy's review of the failings in paediatric cardiac surgery in Bristol during the 1980 s and $90 \mathrm{~s}^{2}$ to Robert Francis's inquiry into the systemic failings at Mid Staffordshire Hospital Trust over a decade later, ${ }^{1}$ culture has been implicated.

\section{Culture as culprit}

"There was an insular 'club' culture [at Bristol], in which it was difficult for anyone to stand out, to press for change, or to raise questions and concerns" (p302) $)^{2}$

"Aspects of a negative culture have emerged at all levels of the NHS system. These include: a lack of consideration of risks to patients, defensiveness, looking inwards not outwards, secrecy, misplaced assumptions of trust, acceptance of poor standards, and, above all, a failure to put the patient first in everything done" (p2357)

\section{Culture as remedy}

"The culture of healthcare, which so critically affects all other aspects of the service which patients receive, must develop and change" (p277) ${ }^{2}$

"The extent of the failure of the system shown in this inquiry's report suggests that a fundamental culture change is needed" (p65)

Ideas of culture are also central to quality improvement methods. From basic clinical audit to sustained improvement "collaboratives," business process re-engineering, Lean Six Sigma, the need for cultural reorientation is part of the challenge. ${ }^{6}$ Yet although the language of organisational culture-sometimes culprit, sometimes remedy, and always part of the underlying substrate at which change is directed-has some immediate appeal, we should ask deeper questions. What actually is culture in health services? How does culture relate to healthcare quality, safety, and performance? And can changing culture lead to improvements in care and organisational performance? 
Greater specificity around both culture and performance enables us to understand more precisely the possible relations between them: quality improvement work is ill served by broadbrush accounts of culture and service quality. We seek to move past the use of culture as simply a rhetorical tool used by politicians and in policy edicts. Instead, we outline a more nuanced account of the social dynamics of healthcare services.

\section{What is culture in this context?}

Healthcare organisational culture (from here, just culture) is a metaphor for some of the softer, less visible, aspects of health service organisations and how these become manifest in patterns of care. The study of organisational practices derives from social anthropologists' approaches to the study of indigenous people: both seek to unravel the dynamics of unfamiliar "tribes." The view that culture can be managed to remedy past deficits and produce desirable future outcomes is often smuggled in through this re-application of the ideas of culture to organisations. This view needs some critical scrutiny, ${ }^{5}$ one that explores a more nuanced account of organisational culture in healthcare.

In one common framing, ${ }^{7}$ the shared aspects of organisational life - the culture-are categorised as three (increasingly obscured) layers (box 2). First, and most visible, are the physical artefacts and arrangements, as well as the associated behaviours that get things done. These visible manifestations of culture are seen in how estate, equipment, and staff are configured and used, and in the range of behaviours seen as normal and acceptable. These include the embedded and accepted care pathways, clinical practices, and communication patterns, sometimes referred to as "the way things are done around here."

Box 2: Three levels of organisational culture in healthcare ${ }^{78}$

Visible manifestations of healthcare culture include the distribution of services and roles between service organisations (such as the long established divides between secondary and primary care and between health and social care), the physical layouts of facilities (receptionists behind desks and doctors in consulting rooms), the established pathways through care (including the ubiquitous outpatients appointment), demarcation between staff groups in activities performed (and the tussles that challenge or reinforce these), staffing practices and reporting arrangements, dress codes (such as different coloured scrubs for different staff groups in emergency departments), reward systems (pay and pensions, but also the less tangible rewards of autonomy and respect), and the local rituals and ceremonies that support approved practices. Visible manifestations of culture (sometimes called artefacts) also include the established ways (both formal and informal) of tackling quality improvement and patient safety, the management of risk, and the accepted ways of responding to staff concerns and patient feedback or complaints.

Shared ways of thinking include the values and beliefs used to justify and sustain the visible manifestations above and their associated behaviours, as well as the rationales put forward for doing things differently. This might include prevailing views on patient needs, autonomy, and dignity; ideas about evidence for action; and expectations about safety, quality, clinical performance, and service improvement.

Deeper shared assumptions are the (largely unconscious and unexamined) underpinnings of day-to-day practice. These might include ideas about appropriate professional roles and delineations; expectations about patients' and carers' knowledge and dispositions; and assumptions about the relative power of healthcare professionals-collectively and individually -in the health system.

The second level is the shared ways of thinking that are used to justify the visible manifestations (box 2). This includes the beliefs, values, and arguments used to sustain current patterns of clinical practice. In this way, the local clinical culture is expressed not only through what is done, but also how it is talked about and justified.

Deeper still, and thus much less overt and accessible, are the largely unspoken and often unconscious expectations and presuppositions that underpin both dialogue and clinical practice (the shared assumptions; box 2). Such attitudes may be formed early, go deep, and be less amenable to modification.
These three levels are linked, of course, but not simply. Some of the deeper values and assumptions are taught in early professional education (the so-called hidden curriculum), reinforced through ongoing professional interactions, and then made visible as accepted practices. Other cultural manifestations are created or shaped externally, perhaps by the macro policy environment (for example, service configurations or reward systems), but over time these can influence shared ways of thinking and even deeper assumptions (about who or what is valued, for example). As healthcare becomes more global, with regular movement of care staff across national borders, major shapers of the cultural aspects of care may also include national, ethnic, or religious cultures.

Organisational culture, then, covers how things are arranged and accomplished, as well as how they are talked about and justified - that is, the stories and narratives about what is done and why, and the presuppositions that underpin these. Taken together these can reflect a shared and commonly understood view of hospital life manifested in patterns of care, safety, and risk. Although we focus on the hospital environment here, these arrangements and narratives are found (albeit in different forms) across all healthcare organisations from general practices to community trusts. Those wishing and situated to improve services need a sophisticated understanding of the social dynamics and shared mental schema that underpin and reinforce existing practices and inform their readiness to change.

An important additional layer of complexity is that shared mental schema may be confined to subgroups within care services, with important implications for patient experience and service delivery.

\section{One culture or many subcultures?}

Healthcare organisations are notoriously varied, fractured by specialty, occupational groupings, professional hierarchies, and service lines. Some cultural attributes might be widespread and stable, whereas others may be shared only in subgroups or held only tentatively. Important subcultures are delineated most obviously, as professional groups, and the faultlines are most obvious as these groups compete for resources and status. ${ }^{9}$ Other subcultures can emerge over time. Some staff groupings may excel at articulating and enacting desirable values and practices, which may be helpful to organisational goals; for example, specialist teams or centres of excellence. Less helpfully perhaps, other subgroups may actively work to undermine changes promoted from external sources (often construed as countercultures). Whether such countercultures reflect unwarranted resistance to change or a more appropriate defence of enduring values may be hard to discern and depends on both perspective and context.

Hospitals, then, are a dynamic cultural mosaic made up of multiple, complex, and overlapping subgroups with variably shared assumptions, values, beliefs, and behaviours. Two of the major professional groupings concerned with quality improvement-doctors and managers-may differ in several important ways, for example. Doctors may focus on patients as individuals rather than groups and view evidence through a positivist natural sciences lens. Managers may be more concerned with patients as groups and value a social science based experiential perspective. ${ }^{10}$ These cultural divergences have important implications for collaborative work, especially for people in hybrid roles who may either retain a cultural allegiance to their base group or seek to adopt the cultural orientations of their new role. They also form an important target for purposeful cultural reform, which might sometimes 
seek to strengthen current trends or at other times to inhibit them.

In sum, specific subcultures may be powerful catalysts for innovation and improvement or defenders of the status quo (for good or ill); they can be useful safeguards against risk or covert countercultures quietly undermining necessary reforms. Making sense of this subcultural diversity should be an essential part of any cultural "diagnosis" in seeking quality improvement.

\section{Can culture be assessed and managed?}

There are two distinctive views of culture. The first is optimistic about the potential for purposive cultural management, seeing culture as something that an organisation has- an attribute that can be assessed and manipulated to improve care. By contrast, the second view is more concerned with securing insights about organisational dynamics, without focusing on whether they can be manipulated. It sees organisational culture as something the organisation simply is - an account of local dynamics not readily separable from the organisational here-and-now.

These two perspectives take us down different routes of assessing and managing local healthcare cultures. The first emphasises the use of metrics to assess the prevalent organisational culture around a performance domain, such as patient safety. This approach assumes that a strong "safety culture" is associated with better outcomes for patients. Such measures may identify targets for managed change, and repeated measurement may be used to gauge progress against cultural objectives, with the hope that improvements in care will follow (for example, the Safety Attitude Questionnaire; box 3). Many such tools exist to assess different aspects of culture, although the science behind them is often weak ${ }^{11}$ and their reliability and validity are questionable. ${ }^{12}$

\section{Box 3: Two examples of culture assessment tools directed at} patient safety

The Safety Attitude Questionnaire (SAQ) is a major (quantitative) assessment tool developed in the United States and widely used in the NHS to help organisations assess their safety culture and track changes over time. The SAQ is a reworking and refinement of a similar tool widely used in the aviation industry. There are various versions of the SAQ, but these typically comprise some 60 survey items, designed in the form of five point Likert scales, in six safety related domains: safety climate; team work; stress recognition; perceptions of management; working conditions; and job satisfaction. Completed by individuals, scores are then aggregated to give an indication of the overall strength of the organisation's extant safety culture.

The Manchester Patient Safety Framework is a facilitative (qualitative) educational tool. It aims to provide insight into safety culture and how it can be improved among teams and organisations. The tool explores nine dimensions of patient safety and describes what an organisation would look like at different levels of patient safety. Assessment is carried out in facilitator-led workshops, and the assessments can be used to prompt reflections, stimulate discussions, and understand strengths and weaknesses.

The second view seeks to explore local cultural dynamics, often working through dialogue and perhaps using images and narratives rather than measurement instruments. This view is more modest about the potential for manager-led purposeful change but may still see cultural assessment as part of an overall influencing strategy (for example, the Manchester Patient Safety Framework; box 3).

Although both perspectives draw on assessment tools, they do so for different reasons: the first emphasising quantitative measurement to identify targets for change and to track progress (a summative approach); the second using qualitative insights more discursively to prompt reflection, learning, and shared actions (a more formative strategy). In practice, many researchers, organisational leaders, and quality improvement specialists will seek insights from across these approaches, despite the (at times uncomfortable) accommodations needed between their divergent assumptions.

\section{Does culture matter?}

It seems obvious that the shared, cultural aspects of organisational life must have some bearing on organisational outcomes. Yet because of the complexity of healthcare cultures and the ambiguity around health service "success," establishing such links through research is not easy. ${ }^{13}$ Nonetheless, the most recent systematic review of work in this area found a "consistently positive association ... between culture and outcomes across multiple studies, settings, and countries." ${ }^{14}$ So, culture does seem to matter. Individual studies can also offer important actionable insights, such as on the importance of leadership, the need for balanced cultures, and on the contingent nature of the relationships between culture and performance (box 4).

\section{Box 4: Insights from empirical study of the links between culture} and care

\section{The importance of leadership}

A recent intervention study (Leadership Saves Lives) focused on leadership actions to promote positive changes in organisational culture in 10 hospitals in the US. It found that changes in culture over a two year period varied substantially between hospitals. ${ }^{1516}$ In the hospitals that experienced substantial and positive cultural shifts, changes were most prominent in specific domains, such as perceptions of the learning environment, senior management support, and psychological safety. Hospitals with marked positive shifts in culture also experienced significant decreases in risk-standardised mortality rates (in this case for treatment of acute myocardial infarction). These findings from the US show which elements of culture need attention from hospital leaders-in particular, fostering a learning environment, offering sustained and visible senior management support to clinical teams, and ensuring that staff across the organisation feel "psychologically safe" and able to speak up when things are felt to be going wrong.

\section{The need for balanced cultures}

Research has shown that, in addition to cultural types, the balance between different cultures is important. Shortell, for example, found that, in a sample of chronic illness management teams, balance among team members relating to the cultural values of participation, achievement, openness to innovation, and adherence to rules and accountability was positively associated with both the number and depth of changes aimed at improving the quality of care. ${ }^{17}$

\section{The appearance of contingent relationships}

The research indicates that there is no single "best" culture that always leads to success across the full range of performance domains. Instead, the aspects of performance valued in a given culture are enhanced in organisations with strong congruence with that culture. Early studies in Canadian, UK, and US hospitals found, for example, that hospitals with inwardly oriented cultures that emphasised managing through informal interpersonal relationships performed significantly above average on measures of employee loyalty and commitment than those with outward looking cultures ${ }^{18}$ Conversely, hospitals with outward looking cultures and procedural management performed better on measures of external stakeholder satisfaction. More recently, large scale longitudinal research in English NHS hospital trusts ${ }^{19}$ replicated some of these findings.

\section{The influence of the wider organisational environment}

A qualitative case study of six NHS hospitals found clear differences in the cultural profile of "high" and "low" performing hospitals in terms of: leadership style and management orientation; accountability and information systems; human resource policies; and relations with other organisations in the local health economy. ${ }^{20}$ Each of these provides potentially important targets for purposeful cultural change aimed at performance improvement.

Clearly, the relations between culture and quality, safety, or efficiency are unlikely to be straightforward. Culture, although important, offers no "magic bullet"- the challenge becomes one of understanding which components of culture might influence which aspects of performance.

Moreover, any relations between culture and health service outcomes are likely to be mutual and recursive: that is, perceived performance is as likely to shape local healthcare cultures as culture is to shape local healthcare performance. Virtuous circles of high performance leading to reinforcing cultures of high 
expectations may be seen, as can spirals into decline where perceived performance failings lead to demoralisation and resignation to those poor standards. ${ }^{20}$ In these arguments, we can see how narrative practices about performance can have important effects on local cultures and that this has implications for clinician leaders, managers, and policy makers in how they talk about and manage performance and improvement.

\section{Conclusions}

Too often the term culture is used as a metaphor for something the organisation is thought to have. But acknowledging that culture is a complex construct can allow more judicious application of the concept. Paying greater attention to the multilayered and multifaceted complexity underlying the term-and recognising that many and varied cultural subgroups make up our healthcare organisations_-opens new avenues for understanding the deeply social and discursive nature of complex organisations.

How these insights are used in quality improvement depends on both other conceptual framings of the healthcare setting, the aspect of service quality or performance to be improved, and on the precise nature of the quality improvement methods to be used. ${ }^{6}$ For some framings and improvement methods, culture is key; for others, cultural aspects are in the background. Our view is that the cultural dimensions of organisations are an important substrate on which improvement focused change is being sought and that, although never fully manageable, cultures can be better understood and must be purposefully shaped.

Finally, the cultural framing of healthcare organisations draws attention to specific aspects of organisational life: the shared patterns of feeling, thinking, talking, and accomplishing that underpin local practice. In doing so, other equally important aspects of organisational life may be marginalised or neglected, such as individual skill, attitude, and responsibility; governance and performance management arrangements; the macro structural arrangements within which local service lines are embedded; the incentives spread across the system; and the availability of material resources, human capital, and knowledge. Each of these aspects interacts with and can sometimes overwhelm cultural features, with a resultant effect on the ability to shape and improve culture and services. The choice to focus improvement efforts on healthcare culture to the exclusion of, say, policy frameworks or resource constraints, inevitably has political ramifications, and these should be dealt with rather than ignored. Cultural reform in healthcare is no substitute for adequate resourcing. That said, the cultural perspective outlined here provides an insightful way of thinking and a practical set of tools to support wider quality improvement work in healthcare.

\section{Competing interests: None declared.}

Provenance and peer review: Commissioned; externally peer reviewed.

This article is one of a series commissioned by The BMJ based on ideas generated by a joint editorial group with members from the Health Foundation and The BMJ, including a patient/carer. The $B M J$ retained full editorial control over external peer review, editing, and publication. Open access fees and The $B M J$ s quality improvement editor post are funded by the Health Foundation.

1 Francis R. The Mid Staffordshire NHS Foundation Trust public inquiry. 2013. https://www. gov.uk/government/publications/report-of-the-mid-staffordshire-nhs-foundation-trust-publicinquiry

2 Kennedy I. The Report of the Public Inquiry into children's heart surgery at the Bristol Royal Infirmary 1984-1995. Learning from Bristol. 2001. https://psnet.ahrq.gov/resources/ resource/5187/learning-from-bristol-the-report-of-the-public-inquiry-into-childrens-heartsurgery-at-the-bristol-royal-infirmary-1984-1995

3 Gosport Independent Panel. Gosport War Memorial Hospital: the report of the Gosport independent panel. 2018. https://www.gosportpanel.independent.gov.uk/

4 Dixon-Woods M, Baker R, Charles K, etal . Culture and behaviour in the English National Health Service: overview of lessons from a large multimethod study. BMJ Qual Saf 2014;23:106-15. 10.1136/bmjqs-2013-001947 24019507

5 Davies HT, Mannion R. Will prescriptions for cultural change improve the NHS?BM 2013;346:f1305. 10.1136/bmj.f1305 23457210

6 Powell AE, Rushmer RK, Davies HTO. A systematic narrative review of quality improvement models in health care. NHS Quality Improvement Scotland, 2009 Schein E. Organizational culture and leadership. Jossey Bass, 1985.

8 Mannion R. Davies, H Cultures in Healthcare. In: Ferlie E, Montgomery K, Reff Pedersen A, eds. Oxford Handbook of Health Care Management. Oxford University Press, 2016.

9 Powell AE, Davies HTO. The struggle to improve patient care in the face of professional boundaries. Soc Sci Med 2012;75:807-14. 10.1016/j.socscimed.2012.03.049 22633159

10 Davies HT, Nutley SM, Mannion R. Organisational culture and quality of health care. Qual Health Care 2000;9:111-9. 10.1136/qhc.9.2.111 11067249

11 Jung T, Scott T, Davies H, Bower P, Mannion R. Instruments for the exploration of organizational culture. Public Adm Rev 2009;69:1987-109610.1111/j.1540-6210.2009.02066.x.

12 Jung T, Scott T, Davies H, Bower P, Mannion R. Instruments for the exploration of organizational culture. Public Adm Rev 2009;69:1987-9610.1111/j.1540-6210.2009.02066.x.

13 Scott T, Mannion R, Marshall M, Davies $\mathrm{H}$. Does organisational culture influence health care performance? A review of the evidence. J Health Serv Res Policy 2003;8:105-17. 10.1258/135581903321466085 12820673

14 Braithwaite J, Herkes J, Ludlow K, Testa L, Lamprell G. Association between organisational and workplace cultures, and patient outcomes: systematic review. BMJ Open 2017; 7:e017708. . 10.1136/bmjopen-2017-017708 29122796

15 Curry LA, Brault MA, Linnander EL, etal . Influencing organisational culture to improve hospital performance in care of patients with acute myocardial infarction: a mixed-methods intervention study. BMJ Qual Saf2018:27:207-17. 10.1136/bmjgs-2017-006989 29101292

16 Bradley EH, Brewster AL, McNatt Z, etal . How guiding coalitions promote positive culture change in hospitals: a longitudinal mixed methods interventional study. BMJ Qual Saf 2018;27:218-25. 10.1136/bmjqs-2017-006574 29101290

17 Shortell SM, Marsteller JA, Lin M, etal . The role of perceived team effectiveness in improving chronic illness care. Med Care 2004;42:1040-8. 10.1097/00005650-200411000-00002 15586830

18 Gerowitz MB, Lemieux-Charles L, Heginbothan C, Johnson B. Top management culture and performance in Canadian, UK and US hospitals. Health Serv Manage Res 1996;9:69-78. 10.1177/095148489600900201 10156914

19 Jacobs R, Mannion R, Davies HTO, Harrison S, Konteh F, Walshe K. The relationship between organizational culture and performance in acute hospitals. Soc Sci Med 2013;76:115-25. 10.1016/j.socscimed.2012.10.014 23159305

20 Mannion R, Davies HT, Marshall MN. Cultural characteristics of "high" and "low" performing hospitals. J Health Organ Manag 2005;19:431-9. 10.1108/14777260510629689 16375066

Published by the BMJ Publishing Group Limited. For permission to use (where not already granted under a licence) please go to http://group.bmj.com/group/rights-licensing/ permissionsThis is an Open Access article distributed in accordance with the Creative Commons Attribution Non Commercial (CC BY-NC 4.0) license, which permits others to distribute, remix, adapt, build upon this work non-commercially, and license their derivative works on different terms, provided the original work is properly cited and the use is non-commercial. See: http://creativecommons.org/licenses/by-nc/4.0/. 